\title{
Visual Design of Information Chart Study in Information Society
}

\author{
Yuanyuan He \\ School of Art and Design \\ Wuhan Textile University \\ Wuhan, China
}

\begin{abstract}
With the progress of science and technology, the popular of network and electronic devices speed up information expansion. Chart is one of the media of information communications. Visual forms of chart are richer, including different visual reflection forms from static one to dynamic one and from graphic one to space one. In addition, visual language makes new breakthroughs. Based on the introduction to the concept of information chart, the paper, with data analysis and empirical example research methods, studies visual design methods of information chart in the aspects of information architecture, information organization, and visual design of information.
\end{abstract}

Keywords-visual design; information chart; information architecture; information organization

\section{CONCEPT OF INFORMATION CHART}

The word "information" has different meanings in different fields. In the modern society, everyone is dealing with different information every day, such as data statistics of customer questionnaire, personal income and expenditure statistic table, newborn electrocardiogram, map, and world population statistics. Information chart reflects data change in the form of table.

At present, information chart design is still a new subject in China. There is no uniform definition, naming, and key teaching point in international teaching design industry. On the concept of "information chart", Richard Saul Wurman, American famous scholar and chart information designer, put forward the concept of "visual information chart" for the first time. He regarded the design of visual information chart as an information structure form, and argued that the radical task of information structure designer was to design information expression----information structure designer should extract the core from complicated situation and information and show it to audience in the clear and beautiful form ${ }^{[1]}$. It is evident that logicality of information organization and visualization of artistic information chart are important influence factors of information visualization. Therefore, the paper will discuss the concrete methods of information visualization in the aspects of information organization, information architecture, and information visualization.

\section{INFORMATION ORGANIZATION}

Data is fact and digit. It is objective existence and does not change along with people's willing. However, information is chosen and sorted out from massive objective data with the help of human mind.

Information organization refers to the structural relation and hierarchical relation among information. The common information relations include coordinating relation, whole-part relation, inclusion relation, and precedence relation. Organization relation should match objective data logic, and should be objective and real. The process is organizing and summing up on the basis of data collection according to different information clues. The common information clues include time order, location, alphabetical order, category/subject, and rank. "Table. I"

TABLE I. THE CLUE OF INFORMATION ORGANIZATION

\begin{tabular}{|l|l|}
\hline $\begin{array}{c}\text { Clue of Information } \\
\text { Organization }\end{array}$ & \multicolumn{1}{|c|}{ Information Features } \\
\hline Time order & $\begin{array}{l}\text { To narrate the process of event, to } \\
\text { describe the development, change, and } \\
\text { event order in time order }\end{array}$ \\
\hline Location & $\begin{array}{l}\text { To reflect clear routine, mode of } \\
\text { transportation, and local news, climate, } \\
\text { and economic topics according to location }\end{array}$ \\
\hline Alphabetical order & $\begin{array}{l}\text { Surname, product or department name, } \\
\text { service name, and format name are } \\
\text { usually placed in alphabetical order }\end{array}$ \\
\hline Category/ subject & $\begin{array}{l}\text { To set different categories, and to sort out, } \\
\text { conclude, and combine again according to } \\
\text { design purpose }\end{array}$ \\
\hline Rank & $\begin{array}{l}\text { Being applicable to information } \\
\text { architecture analysis of website or mobile } \\
\text { phone menu; to know hierarchical relation } \\
\text { among information directly by sorting out } \\
\text { relations of different ranks }\end{array}$ \\
\hline
\end{tabular}

\section{INFORMATION ARCHITECTURE}

Information design needs to be human centered ${ }^{[2]}$. So information architecture is to subdivide and sort out information again on the basis of information organization according to users' effective information that they focus and 
need. According to cognitive study, our innate cognitive structure could only member 4 or 5 kinds of perception units. Therefore, information architecture is to remove some redundant and useless information and to bring convenience to audience to receive effective information. The logic relation of information architecture directly influences audience's understanding of information. Just like writing or talking, information must be logic and well organized to deliver information to the audience clearly. Churchill said that "houses will influence us after they are built" ${ }^{[3]}$.

London subway map is an influential one. The map, designed by Harry Baker, is the classic work in the history of design of information chart. Compared with previous subway maps, its mainline has been transformed form the original curve line into the straight line, which removes all superficial details except from the line of Thames. The map breaks the restriction of distance and spatial location, and changes the convention that railway maps were drawn according to the practical scale. There has not been mixed and disorderly original information on map but clear route map with stations. As a result, passengers will know the next station clearly and find the most convenient route.

In conclusion, information organization and architecture are foundations of design of information visualization. Information organization is to extract effective information from complicated data. While, information architecture is to sort out and edit information again according to different reading needs to raise reading efficiency. "Fig. 1"

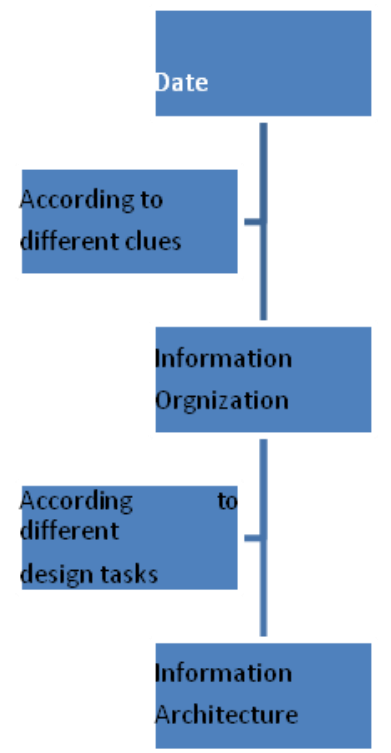

Fig. 1. Information organization to information architecture

\section{Visual Design}

Visual design of information chart is similar with other visual design, which is the perfect combination of function and appreciation. The difference is that information is more accurate, objective, and concrete to meet audience's cognitive needs. Maximo Vignelli, American famous designer, said that "chart should not be cartoon figure or abstract art. It must be complete semantics and effective pragmatism." Therefore, visual communication art of chart must be practical.

The "beauty" of chart lies in "application" of information. Visual design in information chart mainly includes letter, digit, figure, and color. "Fig. 2"

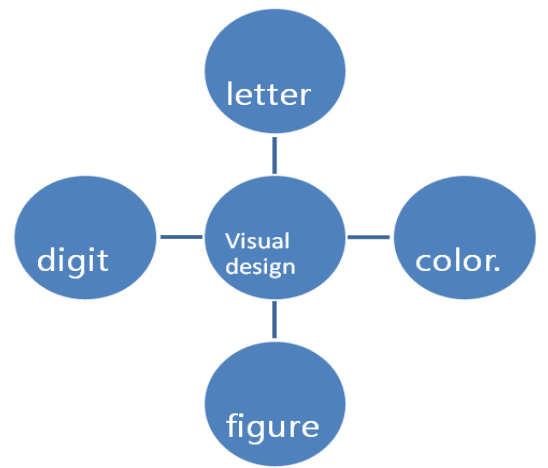

Fig. 2. Design element of information chart

\section{A. Letter}

Letters are often used as title in information chart or appear as note to do supplementary remarks on what the chart wants to deliver to make information more detailed and accurate.

Under some circumstances, letters could become major visual elements in information chart to deliver information. In information chart, all information will be in the limited space, so size, interval, location, character style, and actual situation of letters have influence on people's understanding directly. Form change and relevant objective information have close association.

For example, the information chart showed events in 2007 with letters in "Fig 3", "Fig 4", "Fig 5", "Fig 6" and the size of letters changed according to importance of events. Therefore, designers should not change the form of letters casually due to their aesthetic need.

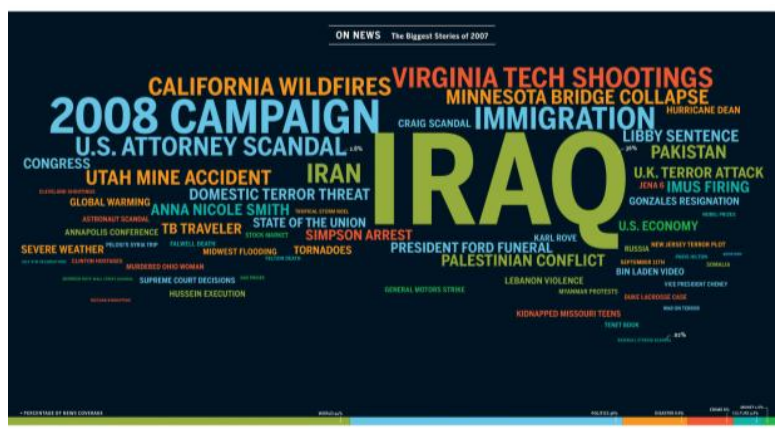

Fig. 3. Event in 2007, fromwww.tuyansuo.com 


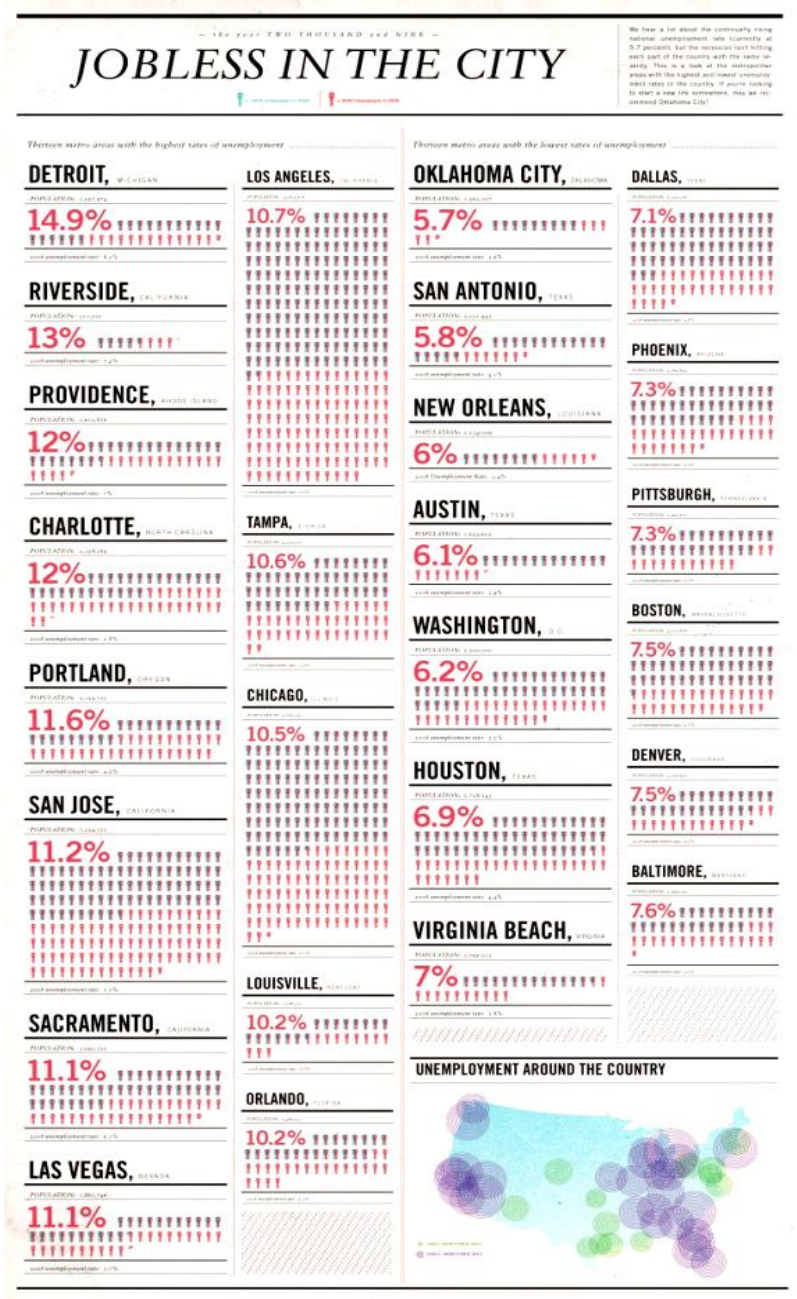

Fig. 4. Unemployment in City, from "www.tuyansuo.com"

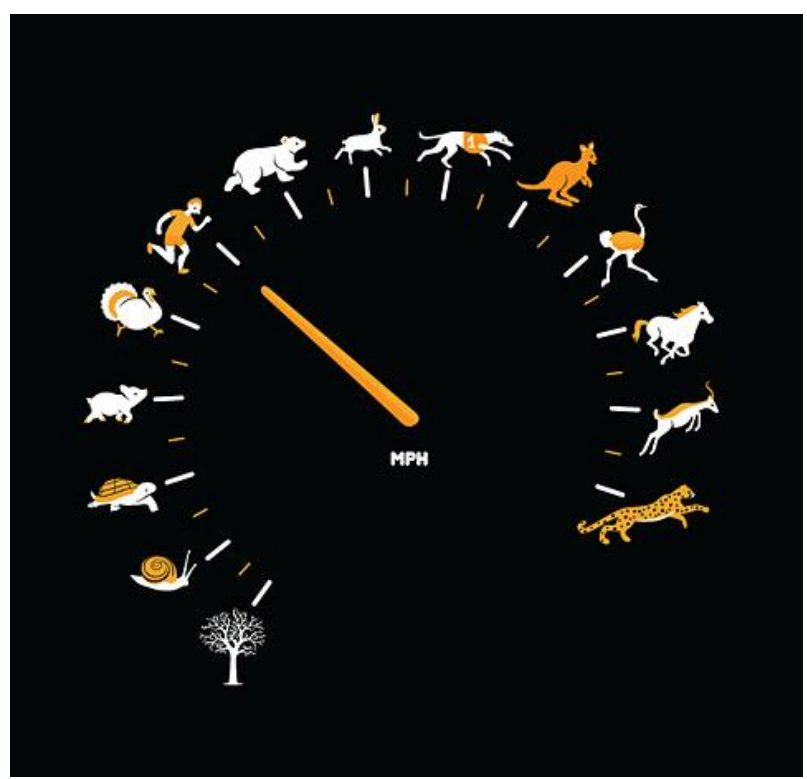

Fig. 5. Speed, from "www.tuyansuo.com"

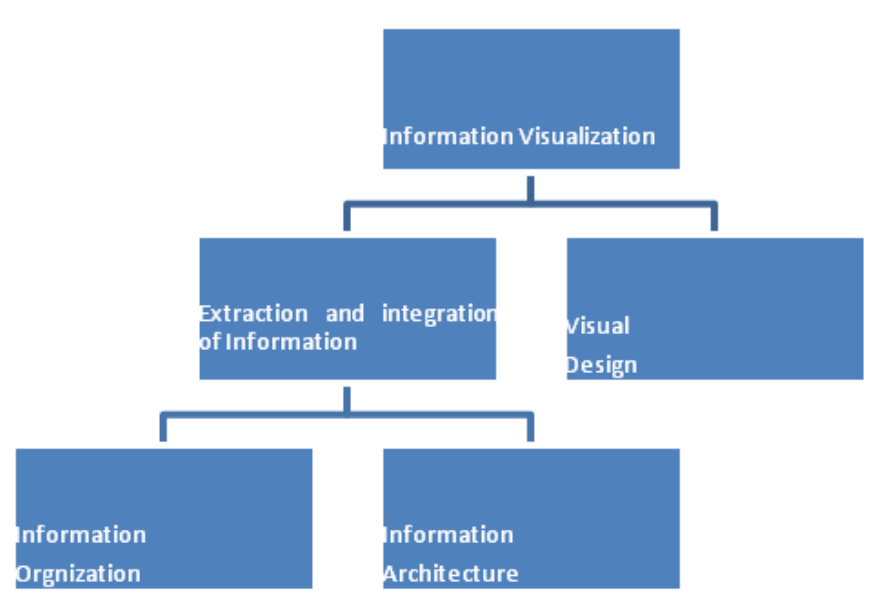

Fig. 6. The process of information visualization

\section{B. Digit}

Digit usually represents relevant data, amount, and time in information chart, so information becomes more powerful, accurate, and real, and hierarchical relation and precedence relation could be reflected clearly. When digits represent amount, they emphasize statistics and comparison of different things. Digits also represent time to describe process and order. Unemployment in City shows the unemployment situation of different cities in USA. The digits in the chart reflect the ratio of unemployment accurately and make the chart be more persuasive.

\section{Figure}

Readers tend to have common sense on figures, so cultural connotation and appeal that figure symbols represent is more direct. However, design objects are different, so the design of figures needs to consider people's thinking habit and cognitive level and to deliver the meaning of figures accurately.

With distinct diagrams, some boring data and complicated concepts in information chart become vivid and expand the semantic meanings of letters. They try to help readers build mental space and imagination space on the modeling of figures, to strengthen the reading sequence of information in chart, to make information be more emotional, and to deliver semantic meaning conveniently and fast. Fig4-9 ranks the sports speed of animals from slow one to fast one. The expression of figures is not accurate than that of digits, but they deliver information to readers in the vivid way.

\section{Color}

Color not only can convey emotion and vivify design, but also can deliver information, such as traffic lights and colors of 
army uniforms. Compared with other visual design, apart form conveying emotion, colors in chart also emphasize semantic features and represent some abstract concepts that are hard to be conveyed, which reduce the load of letters and figures on delivering information in chart.

Concretely speaking, color features in information chart are mainly reflected in the following aspects. First, colors are used to differentiate categories. In the premise of no change of figure and image, different colors can be affirmed with the attribute of objects to divide them into different categories. Different colors are often used in statistic chart to differentiate different objects, and different colors are also used in maps to divide different regions and routes. Second, colors are used to represent the change of objects. The change of color brightness and pureness are often used in information chart to represent the change of objects, such as time change, mood change, or change of appearance. Third, colors are used to indicate primary and secondary relation. Design can emphasize the key points by improving the pureness of colors to make information be clearer and highlight hierarchical relation. On the contrary, the relatively less important information can reduce color pureness or brightness. Fourth, colors can meets emotional needs. People tend to have different emotions when they watch a black-and-white film and colored film. People, with their experience, usually have common mental understanding of colors. Information chart should choose proper colors according to information content, and adjust design without influencing information delivery. Only in this way, can ambiguity be avoided.

\section{CONCLUSION}

The purpose of visual communication of information chart is to delivery real and accurate information to audience in the form of art, to guide their behaviors with understanding of information, and to realize good visual communication. With analysis, content of visual design and its logic structure in information chart have close relationship with information architecture. Information architecture is the basis and source of visual communication, and its process restricts design content, and layout and organizing pattern. Therefore, the design of information chart is the integration of reason and sense, and is the perfect combination of science and art as well.

\section{REFERENCES}

[1] Wang Wei, "Designning Visual Information Chart in information Age" Zhuangshi. Beijing, pp. 128, April 2006.

[2] O'Grady,J.V, O'Grady,K.V, Information Design. Yilin Press,2009.

[3] Peter Morville, Louis Rosenfeld, Information Architecture for the World Wide Web. Publication House of Electronics Industry,2008.

[4] Ye Ping, Chart Design. Jiangxi Fine Arts Design Publishing House, 2010 .

[5] Randy Krum, Cool Infographics: Effective Communication with Date Visualization and Design. Publication House of Electronics Industry, 2014

[6] Alberto Cairo, The Function Art: An Introduction to Information Graphics and Visualization. Posts \&Telecom Press,2015.

[7] Hiroyuki Kimura, Info graphics. Posts \& Telecom Press,2013.

[8] Nathan Yau, Date Points. China Renmin University Press,2014.
[9] Dona M.Wong, The Wall Street Journal Guide to Information Graphics. Zhejiang People Publishing House,,2013.

[10] Mark Smiciklas, The Power of Infographics:Using Picture to Communicate and Connect with Your Audiences. Posts \&Telecom Press,2013. 